\title{
Metal-Metal Bonding Process Using Cu+Ag Mixed Nanoparticles
}

\author{
Jianfeng Yan ${ }^{1}$, Guisheng Zou ${ }^{1}$, Yingchuan Zhang ${ }^{1}$, Jiaxin Li $^{1}$, \\ Lei Liu ${ }^{1}$, Aiping $\mathrm{Wu}^{1}$ and $\mathrm{Y}$. Norman $\mathrm{Zhou}^{1,2}$ \\ ${ }^{1}$ Department of Mechanical Engineering, Tsinghua University \& Key Laboratory for Advanced Materials Processing Technology, \\ Ministry of Education of China, Beijing 100084, P. R. China \\ ${ }^{2}$ Centre for Advanced Materials Joining, Department of Mechanical and Mechatronics Engineering, University of Waterloo, \\ 200 University Avenue West, Waterloo, ON, N2L 3G1, Canada
}

\begin{abstract}
The $\mathrm{Cu}+\mathrm{Ag}$ mixed nanoparticles were prepared based on the chemical reduction method. The polymer coated on the $\mathrm{Cu}+\mathrm{Ag}$ mixed nanoparticles can protect $\mathrm{Cu}$ nanoparticles from oxidation. The metal-metal joint of silver plated $\mathrm{Cu}$ bulks was investigated with the use of $\mathrm{Cu}+\mathrm{Ag}$ mixed nanoparticles. The bonding experiments show that joint with shear strength about $20 \mathrm{MPa}$ was formed at the bonding temperature above $250^{\circ} \mathrm{C}$ under $5 \mathrm{MPa}$ using $\mathrm{Cu}+\mathrm{Ag}$ mixed nanoparticles. The strength of bonding using $\mathrm{Cu}+\mathrm{Ag}$ mixed nanoparticles is lower than that of bonding using pure Ag nanoparticles. This may be due to the fact that the sintering between the $\mathrm{Cu}$ nanoparticles and $\mathrm{Ag}$ nanoparticles is more difficult than the sintering between Ag nanoparticles. [doi:10.2320/matertrans.MD201222]
\end{abstract}

(Received December 17, 2012; Accepted February 25, 2013; Published May 25, 2013)

Keywords: copper+silver mixed nanoparticles, sintering, bonding, electronics packaging

\section{Introduction}

Tin-lead solders have been widely used as bonding materials in the electronics industry for many years. However, since the lead contained in the solders do harm to natural resources and human health, legislation has proposed to limit the use of lead in solders in many countries. ${ }^{1)}$ This situation has stimulated substantial research and development efforts to discover alternative lead-free solder alloys, including $\mathrm{Sn}-\mathrm{Zn}, \mathrm{Sn}-\mathrm{Cu}, \mathrm{Sn}-\mathrm{Bi}, \mathrm{Sn}-\mathrm{Ag}$ systems. ${ }^{2,3)}$ There are still some drawbacks that limit extensive applications of lead-free solders, such as high melting temperatures, poor wettability and poor solderability. Especially, there are no suitable lead-free high temperature solders. The high temperature solders containing 9095 mass $\% \mathrm{~Pb}$ are still widely used in various applications. ${ }^{4)}$

Recently, there has been an increasing focus on low temperature interconnect technologies with metal nanoparticles (Ag nanoparticles, $\mathrm{Cu}$ nanoparticles. etc.) as an alternative technique for the soldering with lead. ${ }^{5-8)}$ The interconnect technologies have potential application for flexible electronics, including flat-panel display, organic electronics, and low-cost disposable microelectronics devices on plastic substrate, ${ }^{7-9)}$ Furthermore, metal nanoparticles provide a promising lead-free, high temperature bonding material alternative. ${ }^{6,10,11)} \mathrm{Cu}+\mathrm{Ag}$ mixed nanoparticles have some advantages such as lower cost and good resistance to electrical migration. ${ }^{12)}$ In this study, the metal to metal bonding process using $\mathrm{Cu}+\mathrm{Ag}$ mixed nanoparticles was studied. The polymer coated on the $\mathrm{Cu}+\mathrm{Ag}$ mixed nanoparticles can protect them from oxidation. The effects of bonding temperatures and $\mathrm{Cu}$ content in the mixed nanoparticles on the bondability were discussed.

\section{Experimental}

Ag nanoparticles was prepared by the polyol method and the following centrifugation as reported previously. ${ }^{13,14)}$ The $\mathrm{Cu}$ nanoparticles was prepared in ambient atmosphere based

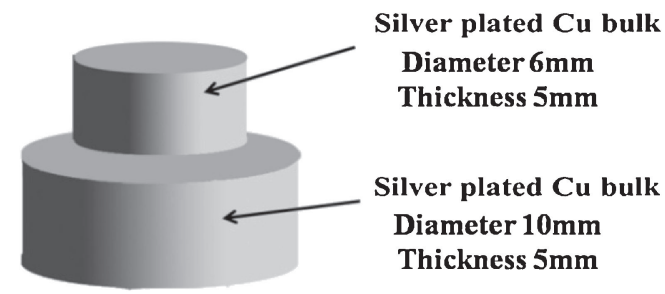

Fig. 1 Schematic illustration of the bonding specimens using $\mathrm{Cu}+\mathrm{Ag}$ mixed nanoparticles.

on the polyol method. ${ }^{8)} \mathrm{Cu}+\mathrm{Ag}$ mixed nanoparticles with different molar fractions $(\mathrm{Cu} / \mathrm{Ag}$ molar ratio: $\mathrm{Cu}, \mathrm{Cu} 4 / \mathrm{Ag} 1$, $\mathrm{Cu} 1 \mathrm{Ag} 1, \mathrm{Cu} 1 \mathrm{Ag} 4$ and $\mathrm{Ag}$ ) were prepared by mechanical mixing of $\mathrm{Cu}$ nanoparticles and $\mathrm{Ag}$ nanoparticles.

The silver plated $\mathrm{Cu}$ bulks were bonded using $\mathrm{Cu}+\mathrm{Ag}$ mixed nanoparticles at $250^{\circ} \mathrm{C}$ in air under bonding pressure of $5 \mathrm{MPa}$ and held for $5 \mathrm{~min}$. The silver plated copper discs were made by firstly plating a layer of nickel (about $2 \mu \mathrm{m}$ ) on the pure copper discs. Then silver plating (about $4 \mu \mathrm{m}$ ) was applied over the nickel plating. Figure 1 shows the schematic illustration of the bonding specimens. The nanoparticles were applied on the faying surfaces of $\Phi$ $6 \mathrm{~mm} \mathrm{Cu}$ bulk, which was set on the $\Phi 10 \mathrm{~mm} \mathrm{Cu}$ bulk. Afterwards, these prepared bonding specimens were heated up to bonding temperature in a resistance furnace in air under $5 \mathrm{MPa}$.

\section{Result and Discussion}

\subsection{Characteristics of nanoparticles}

Figure 2 shows scanning electron microscopy (SEM) and transmission electron microscopy (TEM) images of Ag nanoparticles and $\mathrm{Cu}$ nanoparticles, which were synthesized by chemical reduction method, respectively. Most of $\mathrm{Cu}$ nanoparticles and Ag nanoparticles reveal spherically shaped particles. The polymer coated on the surface of metal nanoparticles can be detected on the TEM images, as shown in Fig. 2. ${ }^{12)}$ It is assumed that the thin layer polymer 

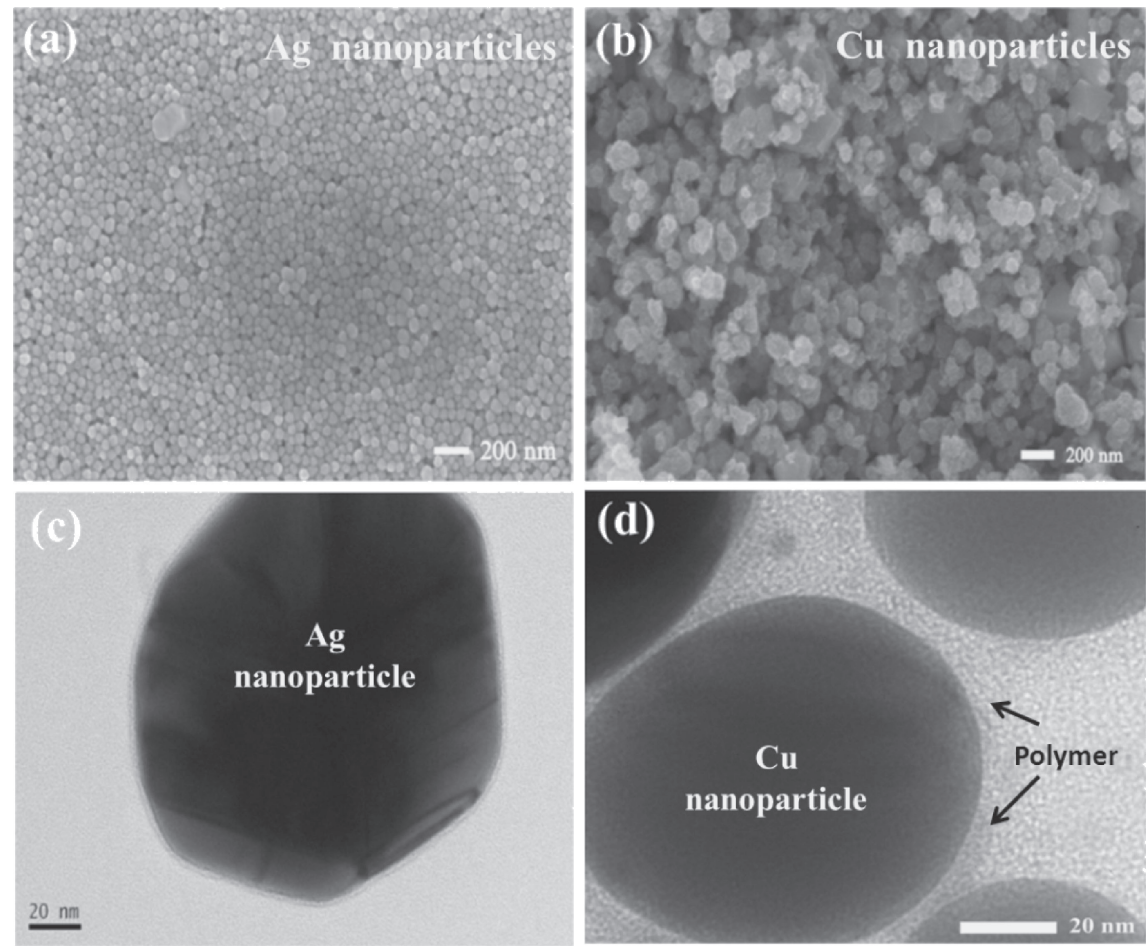

Fig. 2 SEM images of (a) Ag nanoparticles, (b) Cu nanoparticles and TEM images of (c) Ag nanoparticles and (d) Cu nanoparticles.

consisted of polyvinylpyrrolidone can protect $\mathrm{Cu}$ nanoparticles from oxidation when heated in air. ${ }^{8)}$

The reduction mechanism of $\mathrm{Ag}$ nanoparticles by ethylene glycol probably involves the following chemical reactions:

$$
\begin{aligned}
& 2 \mathrm{HOCH}_{2}-\mathrm{CH}_{2} \mathrm{OH} \rightarrow 2 \mathrm{CH}_{3} \mathrm{CHO}+2 \mathrm{H}_{2} \mathrm{O} \\
& 2 \mathrm{CH}_{3} \mathrm{CHO}+2 \mathrm{AgNO}_{3} \\
& \quad \rightarrow \mathrm{CH}_{3} \mathrm{CO}-\mathrm{COCH}_{3}+2 \mathrm{Ag}+2 \mathrm{HNO}_{3}
\end{aligned}
$$

During the synthesis of $\mathrm{Cu}$ NPs, the polyvinylpyrrolidone was used as a protecting agent. Sodium hypophosphite monohydrate $\left(\mathrm{NaH}_{2} \mathrm{PO}_{2} \cdot \mathrm{H}_{2} \mathrm{O}\right)$ was used to reduce copper sulfate pentahydrate $\left(\mathrm{CuSO}_{4} \cdot 5 \mathrm{H}_{2} \mathrm{O}\right)$. The copper ions may be reduced by atomic hydrogen evolving from the reaction of hypophosphite with water, as the following chemical reaction:

$$
\begin{aligned}
& \mathrm{H}_{2} \mathrm{PO}_{2}^{-}+\mathrm{H}_{2} \mathrm{O} \rightarrow \mathrm{H}_{2} \mathrm{PO}_{3}^{-}+2 \mathrm{H} \\
& \mathrm{Cu}^{2+}+2 \mathrm{H}_{2} \mathrm{PO}_{2}^{-}+2 \mathrm{H}_{2} \mathrm{O} \\
& \quad \rightarrow \mathrm{Cu}+2 \mathrm{H}_{2} \mathrm{PO}_{3}^{-}+2 \mathrm{H}^{+}+\mathrm{H}_{2}
\end{aligned}
$$

\subsection{Effect of bonding temperature on bondability}

Figure 3 exhibits the shear strength of joint bonded using $\mathrm{Cu}+\mathrm{Ag}$ mixed nanoparticles (molar ratio $1: 1$ ) as a function of bonding temperatures. When the bonding temperature is $160^{\circ} \mathrm{C}$, the shear strength of the joint is low (about $2 \mathrm{MPa}$ ). As the bonding temperature increased to $200^{\circ} \mathrm{C}$, the shear strength is increased obviously (about $12 \mathrm{MPa}$ ). When the bonding temperature increased to $250-350^{\circ} \mathrm{C}$, the strength is about $20 \mathrm{MPa}$. The small reduction of the joint strength may be related with slight oxidation of $\mathrm{Cu}$ nanoparticles, which need further study.

The fracture surfaces of the joints bonded using $\mathrm{Cu}+\mathrm{Ag}$ mixed nanoparticles (molar ratio $1: 1$ ) at different temperatures are shown in Fig. 4. Different fracture microstructures

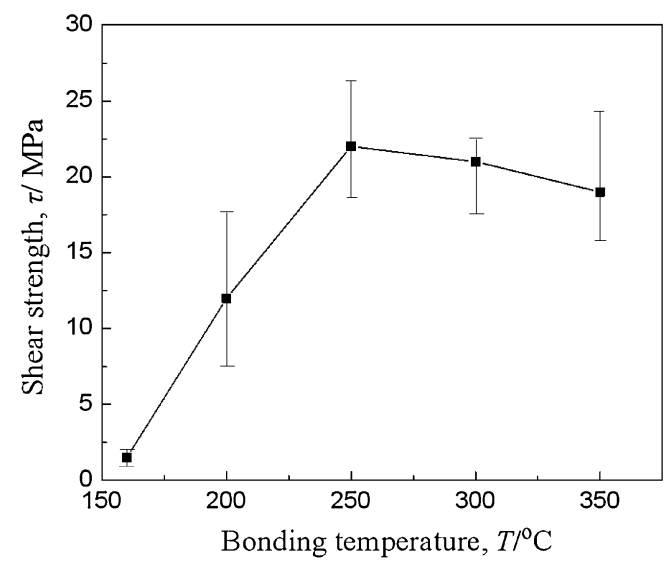

Fig. 3 Shear strength of joint bonded with $\mathrm{Cu}+\mathrm{Ag}$ mixed nanoparticles (molar ratio $1: 1$ ) at different temperatures.

are seen for the joints bonded at different temperatures. At the bonding temperature of $160^{\circ} \mathrm{C}$, the $\mathrm{Cu}+\mathrm{Ag}$ mixed nanoparticles are still encapsulated by polymers. No obvious sintering occurs, which lead to the low bonding strength. As the temperature is increased to $200-350^{\circ} \mathrm{C}$, fracture surfaces show obvious ductile tearing of microstructure between the sintered nanoparticles, which is corresponded to the improvement of the joint strength. ${ }^{15)}$ This result seems to show that strong joint is got when the nanoparticles are sintered together. It is reasonable to deduce that the interparticle bond between the sintered adjacent particles has a significant influence on the joint strength.

The X-ray diffraction (XRD) patterns of fracture microstructure of the joints bonded using mixed $\mathrm{Cu}+\mathrm{Ag}$ nanoparticles at different temperatures are shown in Fig. 5. Peaks attributed to those of metallic $\mathrm{Cu}$ and $\mathrm{Ag}$ are detected. No 

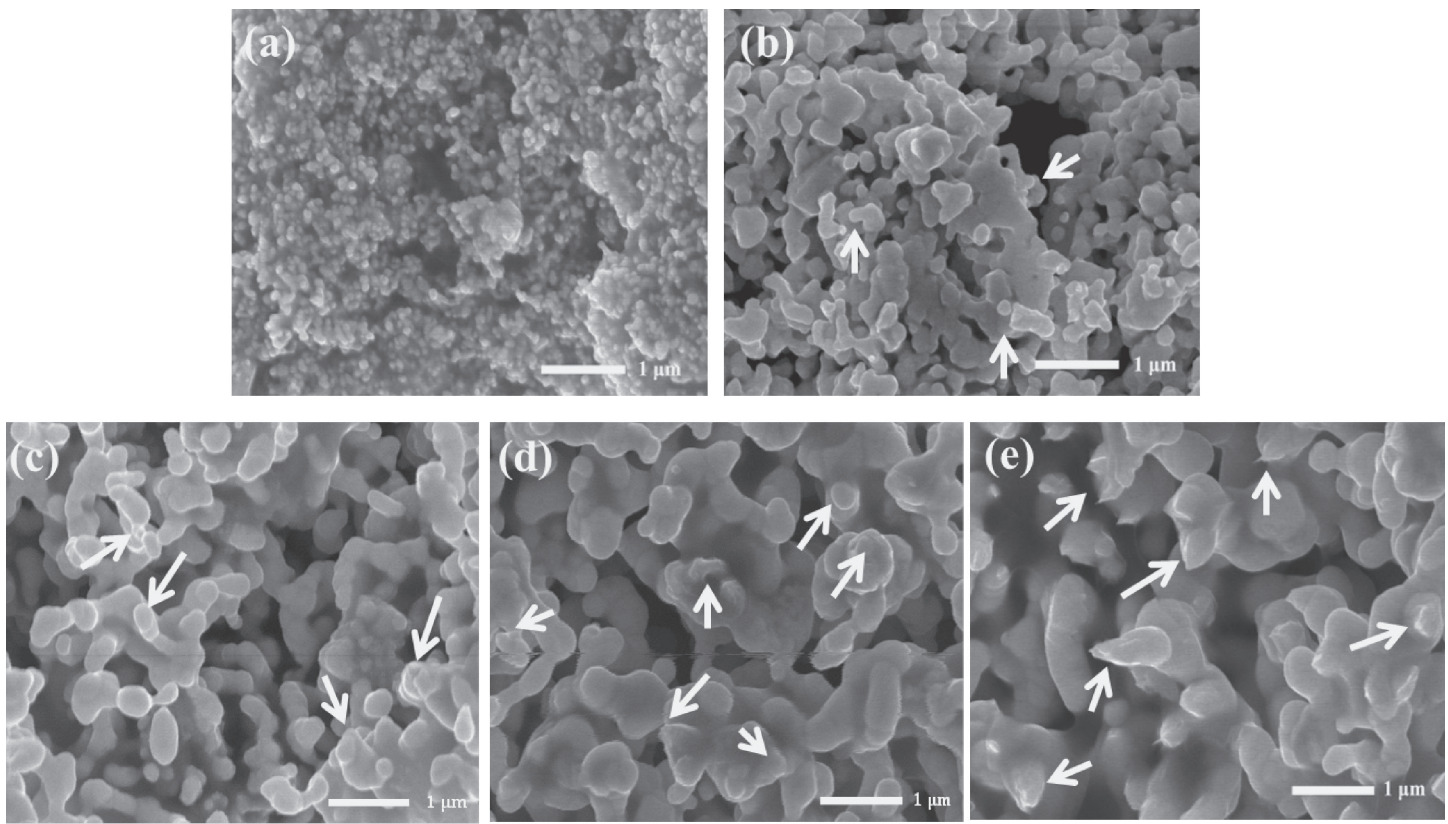

Fig. 4 SEM images of the fracture surface bonded with $\mathrm{Cu}+\mathrm{Ag}$ mixed nanoparticles (molar ratio $1: 1$ ) at different temperatures.

(a) $160^{\circ} \mathrm{C}$. (b) $200^{\circ} \mathrm{C}$. (c) $250^{\circ} \mathrm{C}$. (d) $300^{\circ} \mathrm{C}$. (e) $350^{\circ} \mathrm{C}$. (Arrows show tearing of microstructure between the sintered nanoparticles.)

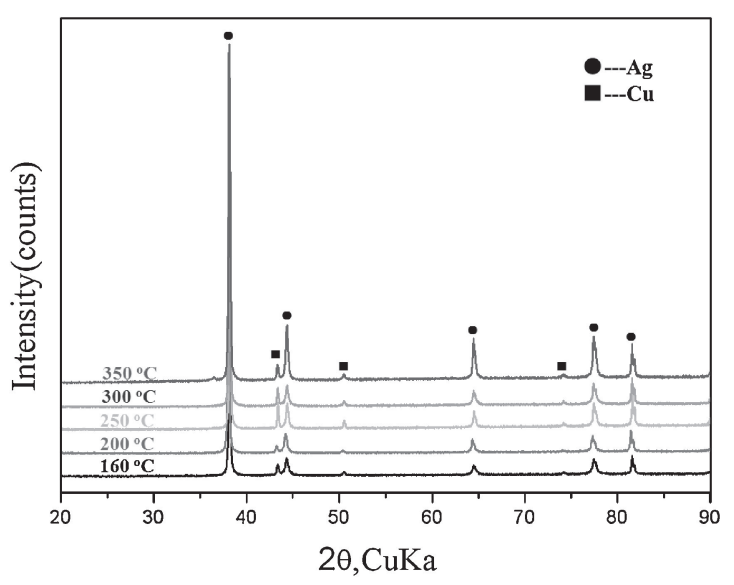

Fig. 5 XRD diffraction patterns of fracture surfaces of the joints boned using mixed $\mathrm{Cu}+\mathrm{Ag}$ nanoparticles at different temperatures (bonding temperatures: $160-350^{\circ} \mathrm{C}$ ).

obvious oxidation peak appears, which indicates that the polymer can protect most of the $\mathrm{Cu}$ nanoparticles from oxidation. It should be note that prevention of the oxidation of copper is important for the improvement the joint quality. ${ }^{8)}$

\subsection{Effect of $\mathrm{Cu}$ content on bondability}

Figure 6 shows the shear strength of the joint bonded using $\mathrm{Cu}+\mathrm{Ag}$ mixed nanoparticles with different $\mathrm{Cu} / \mathrm{Ag}$ molar ratio at $250^{\circ} \mathrm{C}$ under $5 \mathrm{MPa}$. Strong joint is got using $\mathrm{Ag}$ nanoparticles, which has shear strength about $55 \mathrm{MPa}$. However, with the increase of $\mathrm{Cu}$ content in the $\mathrm{Cu}+\mathrm{Ag}$ mixed nanoparticles, the joint strength decreased to about $20 \mathrm{MPa}$. This result is obvious different from that sintering bonding process of copper wire and copper pad, in which the bondability is improved with the increasing of $\mathrm{Cu}$ content in $\mathrm{Cu}+\mathrm{Ag}$ mixed nanoparticles. ${ }^{12)}$ The difference is probably due to the difference of the base metal. Here, the base metal is the silver plated $\mathrm{Cu}$ bulks instead of oxygen free copper wires

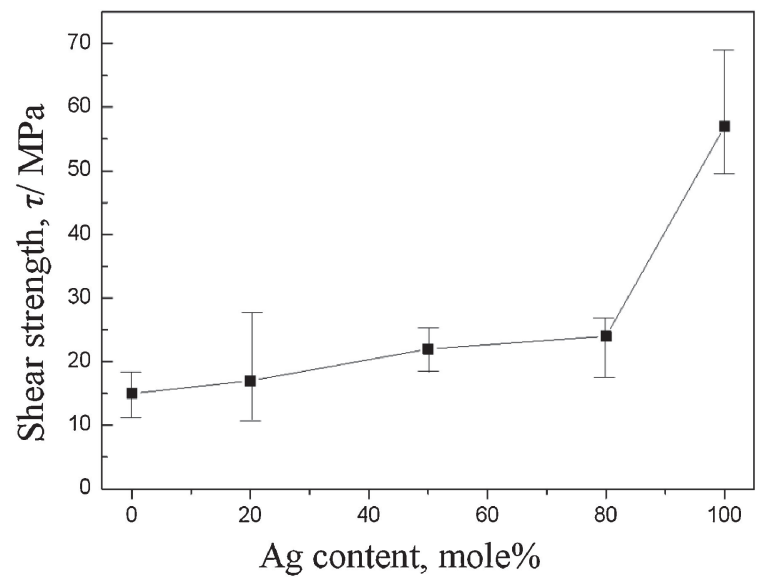

Fig. 6 Shear strength of joints bonded using $\mathrm{Cu}+\mathrm{Ag}$ mixed nanoparticles with different $\mathrm{Cu} / \mathrm{Ag}$ molar ratio $(\mathrm{Cu}, \mathrm{Cu} 4 / \mathrm{Ag} 1, \mathrm{Cu} 1 / \mathrm{Ag} 1, \mathrm{Cu} 1 / \mathrm{Ag} 4$, Ag).

and foils. The strength bonded using $\mathrm{Cu}+\mathrm{Ag}$ mixed nanoparticles is lower than that bonded using pure $\mathrm{Ag}$ nanoparticles. Figure 7 shows the corresponding fracture surfaces of the joint using $\mathrm{Cu}+\mathrm{Ag}$ mixed nanoparticles with different $\mathrm{Cu}$ content. When using pure $\mathrm{Cu}$ nanoparticles as the bonding materials, few tearing of microstructure between the sintered nanoparticles are seen. The joint has a strength of $15 \mathrm{MPa}$. With the increase of the Ag content, more tearing of microstructure can be seen. When using pure $\mathrm{Ag}$ nanoparticles as the bonding materials, the tearing microstructures are obvious. This indicates that the addition of $\mathrm{Cu}$ nanoparticles has an adverse effect on the sintering of nanoparticles.

Figure 8 shows the representative cross sectional image and the element mapping map of the joint boned using $\mathrm{Cu}+\mathrm{Ag}$ mixed nanoparticles (molar ratio $1: 1$ ) at $250^{\circ} \mathrm{C}$ under $5 \mathrm{MPa}$ for $5 \mathrm{~min}$. $\mathrm{Cu}$ nanoparticles which is mixed in the Ag nanoparticles can be detected. Many voids can be seen 

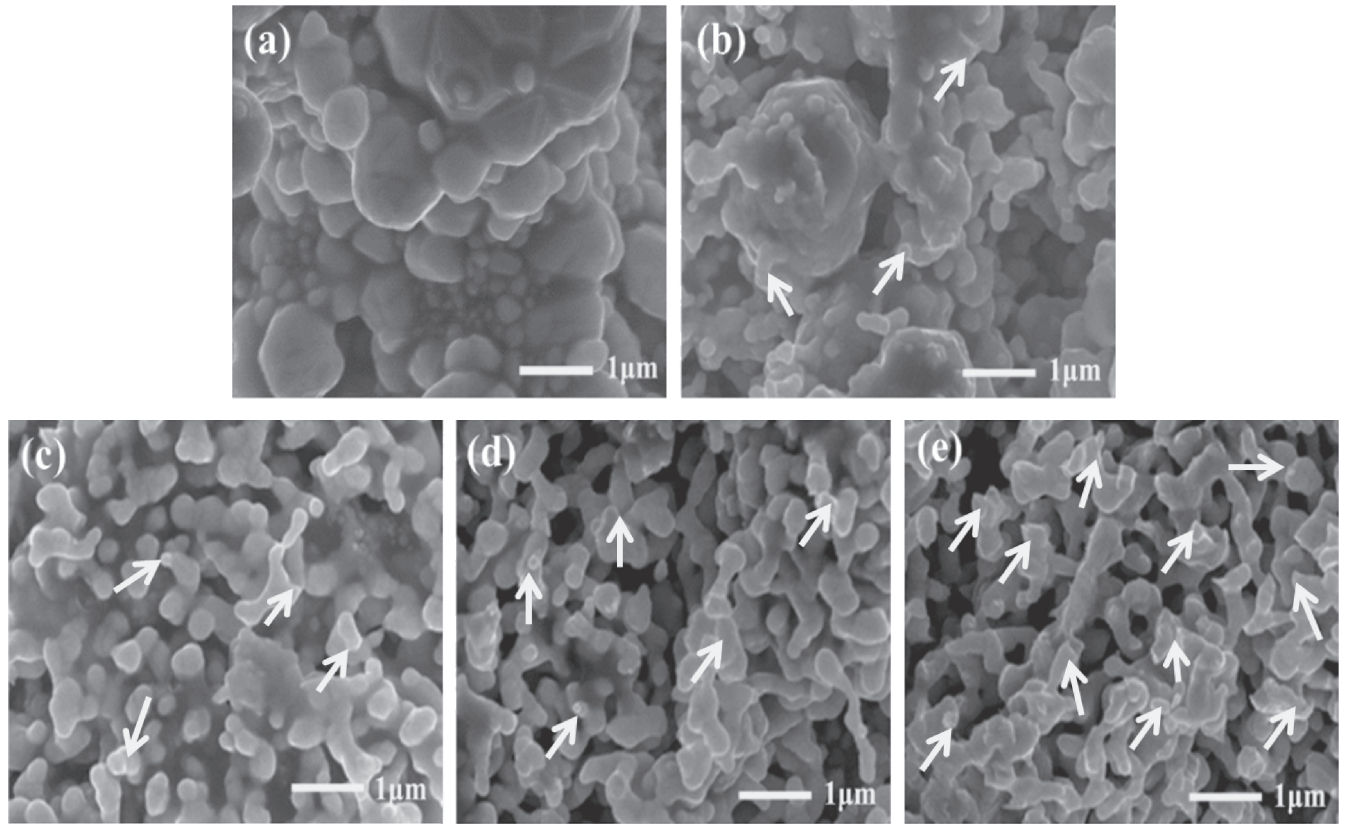

Fig. 7 SEM images of the fracture surface bonded with $\mathrm{Cu}+\mathrm{Ag}$ mixed NPs (different $\mathrm{Cu} / \mathrm{Ag}$ molar ratio). (a) $\mathrm{Cu}$. (b) $\mathrm{Cu} 4 / \mathrm{Ag} 1$. (c) $\mathrm{Cu} 1 /$

Ag1. (d) Cu1/Ag4. (e) Ag. (Arrows show tearing of microstructure between the sintered nanoparticles.)
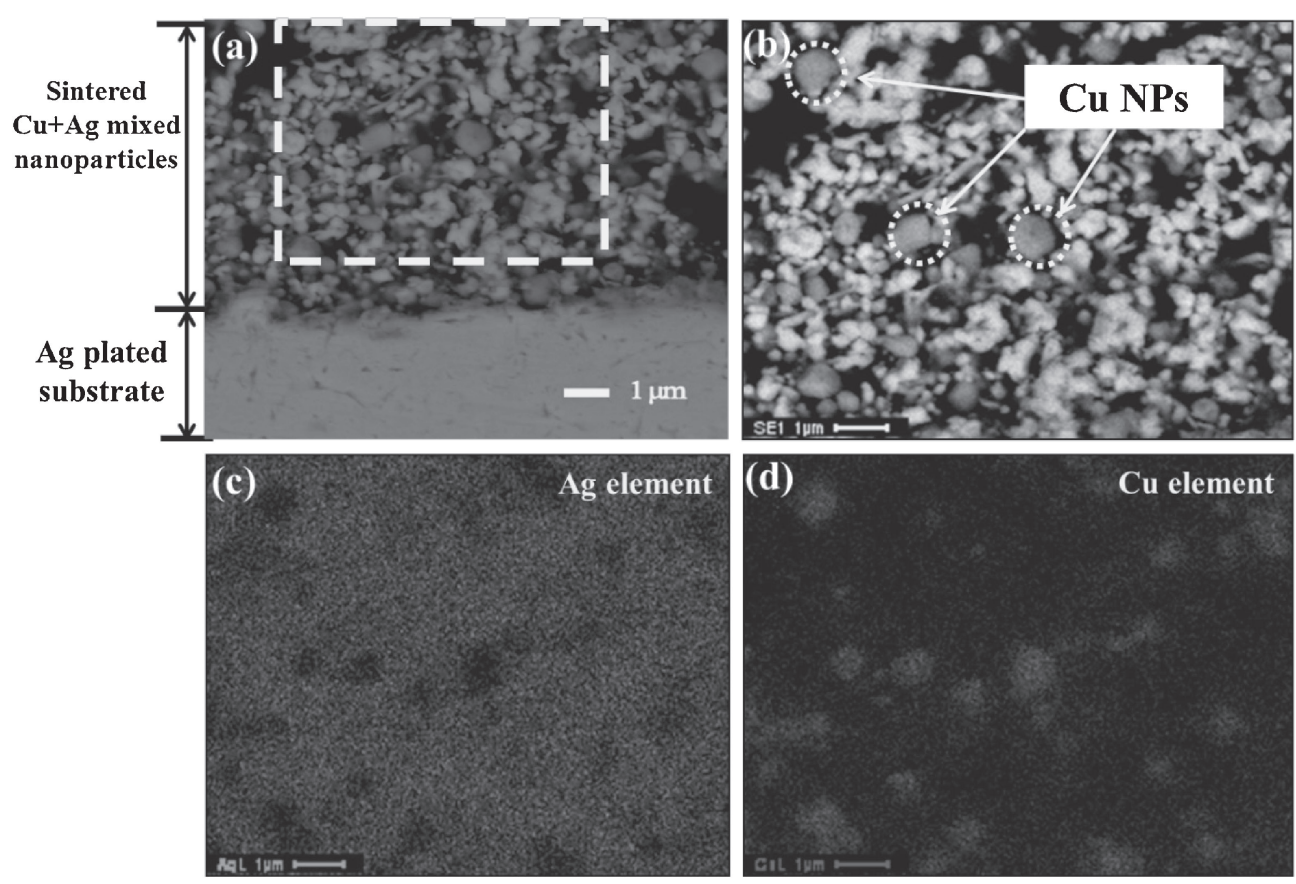

Fig. 8 Representative SEM images cross sectional image of the joint and the element mapping map.

around the $\mathrm{Cu}$ nanoparticles. As mentioned above, the $\mathrm{Cu}$ content has an adverse effect on the joint strength and this may due to the voids near the $\mathrm{Cu}$ nanoparticles. Figure 9 is the SEM images of fracture surface of joint bonded using $\mathrm{Cu}+\mathrm{Ag}$ mixed nanoparticles. Based on the EDX spectra result, it is known that point $\mathrm{A}$ is the sintered $\mathrm{Ag}$ nanoparticles and point $\mathrm{B}$ is consisted of sintered $\mathrm{Cu}$ nanoaprticles. It is interesting that at the region consisted of $\mathrm{Ag}$ nanoparticles the tearing microstructures are obvious. No obvious tearing microstructures at the region consisted of $\mathrm{Cu}$ nanoparticles were seen. These fracture morphologies may indicate that the sintering between the $\mathrm{Cu}$ nanoparticles and the Ag nanoparticles is more difficult than that between $\mathrm{Ag}$ nanoparitlces. It is reasonable to assume that the fracture path is along the $\mathrm{Cu}$ nanoparticles, where lots of voids existed. Based on the above discussion, the possible schematics of the sintering behaviors of $\mathrm{Cu}+\mathrm{Ag}$ mixed nanoparticles and possible crack path in the sintered $\mathrm{Cu}+\mathrm{Ag}$ mixed nanoparticles are shown in Fig. 10. This illustrates that the $\mathrm{Cu}$ nanoparticles is the weak position and the crack path extend along the void around $\mathrm{Cu}$ nanoparticles. Due to these reasons, it is reasonable to deduce that the addiction of $\mathrm{Cu}$ nanoparticles to Ag nanoparticles will reduce the joint strength, which is consistent with the above experimental results. 

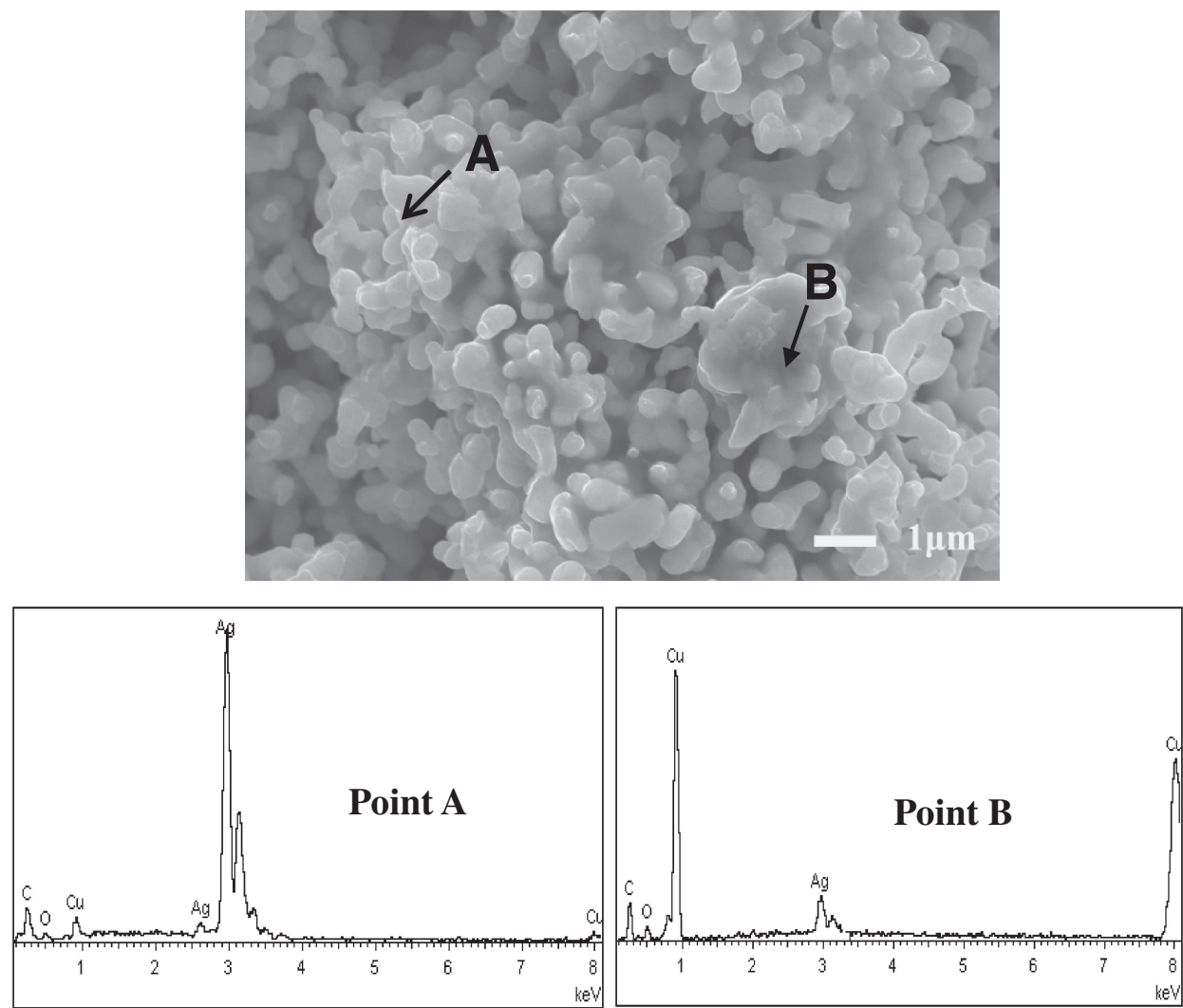

Fig. 9 SEM images of fracture surface of joint made using $\mathrm{Cu}+\mathrm{Ag}$ mixed nanoparticles and the EDX spectra at point $\mathrm{A}$ and at point $\mathrm{B}$.

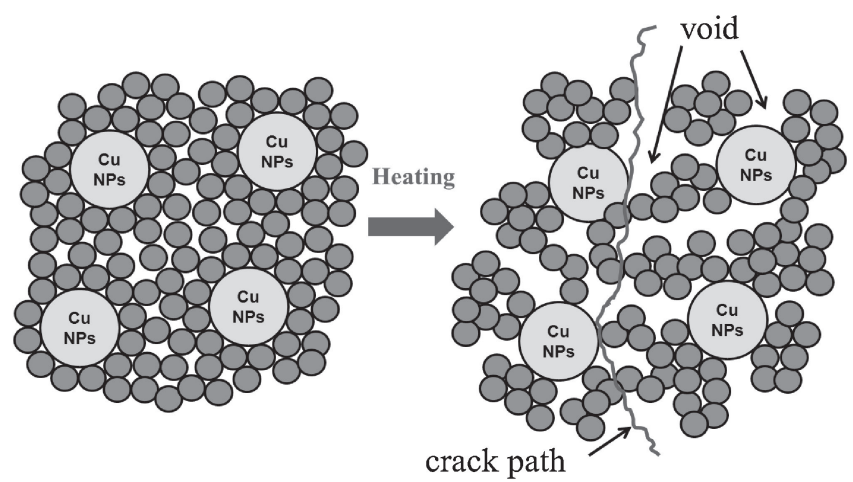

Fig. 10 Schematics of possible sintering behaviors and crack path in the sintered $\mathrm{Cu}+\mathrm{Ag}$ mixed nanoparticles.

\section{Conclusions}

In summary, we have succeeded in the bonding of silver plated $\mathrm{Cu}$ bulks using $\mathrm{Cu}+\mathrm{Ag}$ mixed nanoparticles. No obvious oxidation of $\mathrm{Cu}$ nanoparticles was detected in the fracture surfaces of the joint. The joints with shear strength about $20 \mathrm{MPa}$ was formed at the bonding temperature above $250^{\circ} \mathrm{C}$ under $5 \mathrm{MPa}$ using $\mathrm{Cu}+\mathrm{Ag}$ mixed nanoparticles. The addition of $\mathrm{Cu}$ nanoparticles to $\mathrm{Ag}$ nanoparticles reduces the joint strength. This may due to the addition of $\mathrm{Cu}$ nanoparticles has an adverse effect on the sintering of nanoparticles and many voids exists around the $\mathrm{Cu}$ nanoparticles.

\section{Acknowledgement}

This research was supported by the National Natural Science Foundation of China (Grant No. 51075232) and by Tsinghua University Initiative Scientific Research Program (Grant No. 2010THZ 02-1).

\section{REFERENCES}

1) Y. Li, K. Moon and C. Wong: Science 308 (2005) 1419-1420.

2) K. Suganuma: Curr. Opin. Solid State Mater. Sci. 5 (2001) 55-64.

3) M. Abtew and G. Selvaduray: Mater. Sci. Eng. Rep. 27 (2000) 95-141.

4) H. Ogura, M. Maruyama, R. Matsubayashi, T. Ogawa, S. Nakamura, T. Komatsu, H. Nagasawa, A. Ichimura and S. Isoda: J. Electron. Mater. 39 (2010) 1233-1240.

5) Y. Zhou (ed.): Microjoining and Nanojoining, (Cambridge, 464 UK: CRC/Woodhead, 2008).

6) E. Ide, S. Angata, A. Hirose and K. F. Kobayashi: Acta Mater. 53 (2005) 2385-2393.

7) A. Hu, J. Y. Guo, H. Alarifi, G. Patane, Y. Zhou, G. Compagnini and C. X. Xu: Appl. Phys. Lett. 97 (2010) 153117.

8) Y. Jianfeng, Z. Guisheng, H. Anming and Y. N. Zhou: J. Mater. Chem. 21 (2011) 15981-15986.

9) Q. Cui, F. Gao, S. Mukherjee and Z. Gu: Small. 5 (2009) 1246-1257.

10) T. Morita, E. Ide, Y. Yasuda, A. Hirose and K. Kobayashi: JPN. J. Appl. Phys. 47 (2008) 6615-6622.

11) J. G. Bai and L. Guo-Quan: IEEE. Trans. Device. Mater. Reliab. 6 (2006) 436-441.

12) J. Yan, G. Zou, A. Wu, J. Ren, A. Hu and Y. N. Zhou: J. Electron. Mater. 41 (2012) 1886-1892.

13) Y. Sun and Y. Xia: Science 298 (2002) 2176-2179.

14) J. Yan, G. Zou, A. Wu, J. Ren, A. Hu and Y. Zhou: Scr. Mater. 66 (2012) 582-585.

15) A. Hasnaoui, H. Van Swygenhoven and P. M. Derlet: Science 300 (2003) 1550-1552. 